\title{
CONSIDERATIONS FOR DERIVATION AND USE OF SOIL MOISTURE DATA FROM ACTIVE MICROWAVE SATELLITES AT HIGH LATITUDES
}

\author{
A. Bartsch ${ }^{*}$, D. Sabel, W. Wagner ${ }^{\dagger}$ \\ Institute of Photogrammetry and \\ Remote Sensing \\ Vienna University of Technology \\ Austria
}

\begin{abstract}
Soil moisture is an import parameter for high latitude research focusing on carbon exchange and permafrost issues. This paper reviews requirements, constrains and possibilities of satellite derived soil moisture data for high latitude applications. Major points are freezing and thawing, and landscape heterogeneity. Special focus is on data derived from ENVISAT ASAR. The different ScanSAR modes (wide swath and global monitoring mode) can be used to address various issues. Sensitivity over tundra at this wavelength is similar to semi-arid regions in mediterranean and subtropic climates.
\end{abstract}

Index Terms - soil moisture, arctic, active microwave, SAR, scatterometer

\section{INTRODUCTION}

A range of satellite derived global soil moisture datasets is available to date. They are derived using passive as well as active microwave sensors. Recently launched satellites (Metop ASCAT, SMOS) allow for continuity in monitoring. ScanSAR technology enables the step from coarse (approximately $25 \mathrm{~km}$ ) to medium resolution [1]. The majority of validation and application activities of such datasets has however been carried out in mid to low latitudes only.

There is a clear need of soil moisture monitoring at high latitudes, especially in the context of climate change. Soil moisture together with temperature is a limiting factor for heterotrophic soil respiration. It is thus important for estimation of carbon exchange [2]. Large areas at high latitudes are underlain by permafrost. Any variation in parameters which impact heat conductivity play a role in the reaction of

\footnotetext{
*The first author is recipient of an Elise Richter fellowship by the Austrian Science Fund (FWF)

$\dagger$ This work has been carried out within the framework of the European Space Agency's DUE Permafrost project
}

\author{
S.-E. Park \\ Graduate School of Science and Technology \\ Niigata University \\ Japan
}

the subsurface frozen ground to changes in the atmosphere. Soil moisture information is one of the key parameter for modelling of permafrost extent [3].

Challenges for the derivation of soil moisture in high latitudes are

- frozen/snow covered ground conditions,

- landscape heterogeneity,

- seasonal variation in landcover type (water - nonwater),

- scarcity of ground data

- and issues related to the overlaying vegetation such as moss cover.

These issues are addressed within the ESA DUE Permafrost (www.ipf.tuwien.ac.at/permafrost) and STSE ALANIS (www.alanis-methane.info) projects focusing on time series analysis using $\mathrm{C}$-Band active microwave data from scatterometer (ASCAT) and Advanced Synthetic Aperture Radar (ENVISAT ASAR).

Spatial heterogeneity can be addressed using higher spatial resolution data than what is used for the global products. This has been tested for soil moisture variations [4] as well as related aspects such as frozen ground surface detection [5] and tundra ponds identification [6].

This paper reviews requirements, constrains and possibilities of satellite derived soil moisture data for high latitude applications. Special focus is on data derived based on the concept of time series analyses of active microwave satellite data [7].

This is the accepted version of this conference paper. The final published version (version of record) is available via the DOI https://doi.org/10.1109/IGARSS.2011.6049882

(C) 2011 IEEE. Personal use of this material is permitted. Permission from IEEE must be obtained for all other uses, in any current or future media, including reprinting/republishing this material for advertising or promotional purposes, creating new collective works, for resale or redistribution to servers or lists, or reuse of any copyrighted component of this work in 


\section{FROZEN GROUND AND SNOW COVERED GROUND CONDITIONS}

Active microwave measurements can be used for detection of changes in near surface soil moisture as well as freeze/thaw status. Microwave backscatter differs significantly due to changing dielectric properties between frozen and unfrozen ground (e.g. [8, 9, 10]). In C-band, the summer backscatter is in general higher than when snow is present or the ground is frozen. When the snow surfaces recyristallize after a midwinter short-term melt event, backscatter can increase up to summer levels in C-band [11]. Microwave backscatter during freeze/snow free conditions increases with increasing soil moisture [8]. This has been demonstrated for C-band scatterometer (e.g. [12, 13]). The minimum (dry reference) and maximum (wet reference) values are site specific. Once they have been determined from a sufficiently long enough record each measurement can be scaled between those boundary values and a relative near surface soil moisture content determined. Such datasets are available globally (since 2002, [14]) and in case of ASCAT in near-real-time [15]. They can be thus applied e.g. for operational applications such as assimilation into weather forecasts [16] and due to global coverage for high latitude applications. In order to derive relative soil moisture, a frozen ground detection is required for masking. Snow cover information which is available from a multitude of sensors can be used for approximation, but especially autumn freeze-up can occur without the presence of snow.

The detection of the exact timing of spring thaw and autumn freeze-up requires sufficient temporal sampling. This is available with scatterometer, but challenging when SAR data which offer better spatial resolution are used. ENVISAT ASAR Global Monitoring Mode is available twice a week in some high latitude regions. It has been shown that although there are noise constraints, timing can be determined at this sampling rate [5].

\section{LANDSCAPE HETEROGENEITY AND SEASONAL VARIATIONS}

Tundra regions are often characterized by a high number of small lakes and ponds which can be easily identified with higher resolution microwave satellite data (Synthetic aperture radars - SARs) due to the specific low backscatter of smooth water surfaces (e.g. [6]). For coarse resolution data such as from the ERS scatterometer, however, it has been found that contributions of lakes and rivers to the overall backscatter is very small and can be neglected [11] for freeze/thaw detection. A high open water fraction within the footprint can however have an impact on the dry reference determination for soil moisture retrieval and can introduce a bias. The temporal variation is nevertheless captured. A correction is required if the water fraction within a pixel varies throughout the season. The magnitude of such changes within a summer can be large due to the flat terrain and slow drainage [17].

Variation of backscatter in summer can be also caused by phenology. Backscatter increases with vegetation growth $[18,19]$. The magnitude of contribution at C-band is, however, low compared to soil water changes [20].

Figure 1 shows an example for parameters required for surface soil moisture derivation. The shown region covers arctic and subarctic tundra along the Laptev Sea Coast in Eastern Siberia. Those are coastal lowlands with partly many small lakes. Hilly terrain with bare rock surfaces are visibly in the southwestern part. The parameters have been derived from several year time series from ENVISAT ASAR GM.

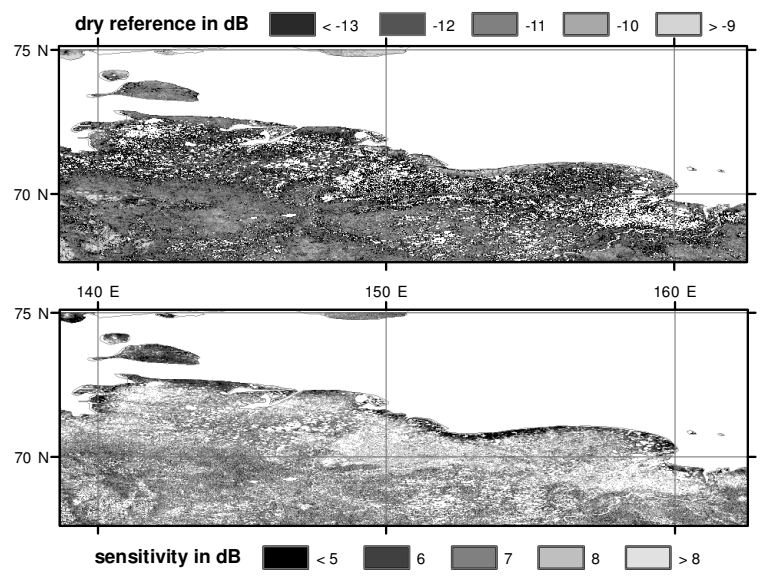

Fig. 1. An example of sensitivity and dry reference in tundra environment along the Laptev Sea Coast region derived from ENVISAT ASAR Global Monitoring mode. Lakes and areas with high water fraction are masked.

The observable summer backscatter range (sensitivity) over tundra at this wavelength is similar to semi-arid regions in mediterranean and subtropic climates with $6-7 \mathrm{~dB}$. It is higher over dwarf shrub tundra than moss dominated wetlands. This can be observed especially along the coast line.

Low backscatter values, less then under dry conditions, are typical for snowmelt conditions (e.g. shown for ASAR global monitoring mode [21]). The initial algorithm does therefore consider only data from the snowfree period. Many tundra regions are permanently moist. The dry reference needs to be therefore adjusted. This can be achieved by inclusion of frozen ground conditions. Figure 2 shows the 


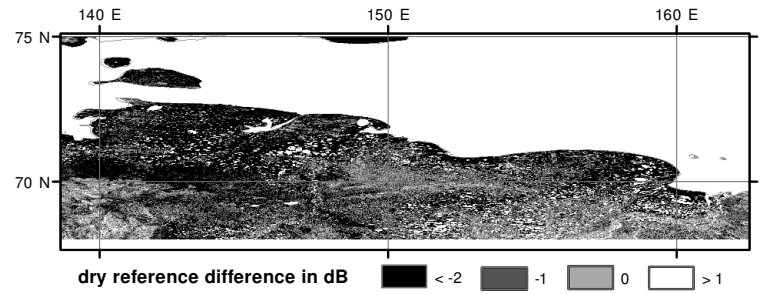

Fig. 2. Difference of corrected dry reference and summer dry reference in tundra environment along the Laptev Sea Coast region derived from ENVISAT ASAR Global Monitoring mode. Lakes and areas with high water fraction are masked.

difference between the calculations, with and without data from the early winter period. The reduction is more than 2 $\mathrm{dB}$ over moist tundra, dominated by tussock cottongrass and abundant moss (Figure 3, as defined in [22]), which accounts for more than $45 \%$ of the landcover in the study area.

\section{GROUND DATA}

Continuous in-situ soil moisture measurements in the arctic are limited. Values are vary considerably from point to pint due to periglacial landscape features such as polygonal ground. Satellite data reflect only the general moisture patterns in a larger region related to variations in precipitation. This has been exemplified for a site in the Lena Delta [23].

\section{CONCLUSIONS}

Specific characteristics of tundra landscapes such as a high open water fraction, freeze/thaw, seasonal inundation and all summer moist conditions need to be considered beside the requirement of continuous data availability when active microwave data are used for soil moisture retrieval. This can be addressed in some cases without auxiliary data (freeze/thaw, dry reference adjustment) and use of further active microwave datasets at different spatial resolutions (heterogeneity). Soil moisture retrieval over longer time periods with active microwave data is currently limited to C-band data due to lack of other suitable records such as L-band. Vegetation canopy does however only have a very small impact on the observable backscatter range (sensitivity). Permanently moist conditions, as typical for some arctic regions, need to be taken into consideration for the determination of the dry reference.

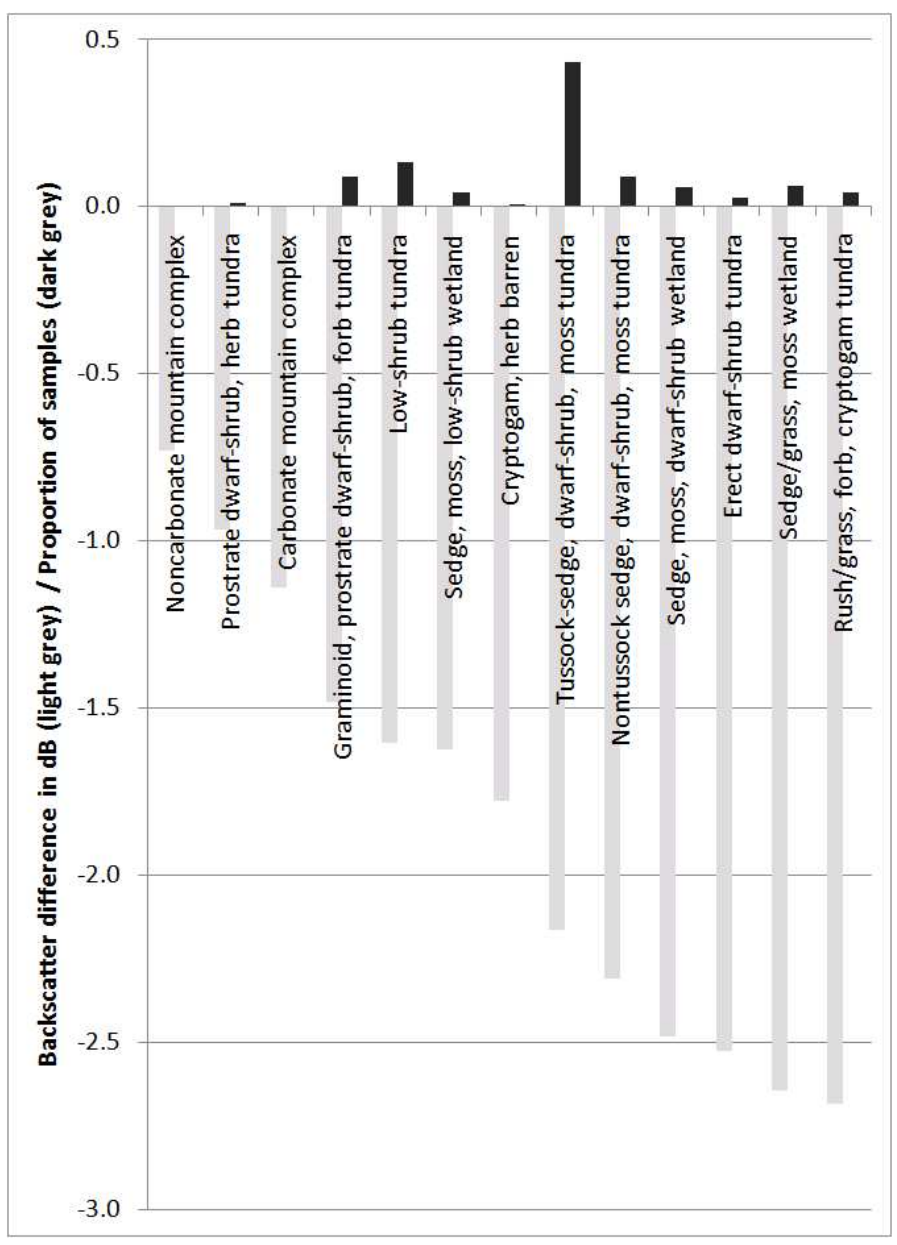

Fig. 3. Difference of corrected dry reference and summer dry reference in arctic tundra environment along the Laptev Sea Coast region (approximately north of 70 degree latitude) derived from ENVISAT ASAR Global Monitoring mode. Vegetation classes from the Circum Arctic Vegetation Map [22].

\section{REFERENCES}

[1] A. Bartsch, M. Doubkova, and W. Wagner, "ENVISAT ASAR GM soil moisture for applications in Africa and Australia," in Proceedings of The Earth Observation and Water Cycle Scieny Conference, Frascati, November 2009, 2009.

[2] J. S. Kimball, L. A. Jones, K. Zhang, F. A. Heisch, K. C. McDonald, and W. C. Oechel, "A satellite approach to estimate land-atmosphere $\mathrm{CO}_{2}$ exchange for boreal and arctic biomes using MODIS and AMSR-E.," IEEE Transactions on Geoscience and Remote Sensing, vol. 47, pp. 569-587, 2009.

[3] S. Marchenko, V. Romanovsky, and G. Tipenko, "Numerical modeling of spatial permafrost dynamics in Alaska," in Proceedings of the Ninth International Sym- 
posium on Permafrost, Fairbanks, Alaska, 2008, pp. 1125-1130.

[4] W. Wagner, C. Pathe, M. Doubkova, D. Sabel, A. Bartsch, S. Hasenauer, G. Blöschl, K. Scipal, J. Martínez-Fernández, and A. Löw, "Temporal stability of soil moisture and radar backscatter observed by the advanced synthetic aperture radar (ASAR)," Sensors, vol. 8, pp. 1174-1197, 2008.

[5] S. E. Park, A. Bartsch, D. Sabel, and W. Wagner, "Monitoring of thawing process using ENVISAT ASAR global mode data," in Proceedings Geoscience and Remote Sensing Symposium (IGARSS), Honolulu, Hawaii, 2010, pp. 2031-2034, IEEE International.

[6] A. Bartsch, C. Pathe, W. Wagner, and K. Scipal, "Detection of permanent open water surfaces in central Siberia with ENVISAT ASAR wide swath data with special emphasis on the estimation of methane fluxes from tundra wetlands," Hydrology Research, vol. 39, no. 2, pp. 89100, 2008.

[7] W. Wagner, G. Lemoine, and H. Rott, "A method for estimating soil moisture from ERS scatterometer and soil data," Remote Sensing of Environment, vol. 70, pp. 191207, 1999.

[8] F. T. Ulaby, R. K. Moore, and A.K. Fung, Microwave Remote Sensing-Active and Passive, vol. II, Artech House, Norwood, Mass., 1982.

[9] J. B. Way, R. Zimmermann, E.. Rignot, K. McDonald, and R. Oren, "Winter and spring thaw as observed with imaging radar at BOREAS," Journal of Geophysical Research, vol. 102, pp. 29673-29684, 1997.

[10] Urs Wegmüller, "The effect of freezing and thawing on the microwave signatures of bare soil," Remote Sensing of Environment, vol. 33, pp. 123-135, 1990.

[11] Volkmar Wismann, "Monitoring of seasonal thawing in Siberia with ERS scatterometer data," IEEE Transactions on Geoscience and Remote Sensing, vol. 38, no. 4, pp. 1804-1809, 2000.

[12] Wolfgang Wagner, Josef Noll, Maurice Borgeaud, and Hemut Rott, "Monitoring soil moisture over the Canadian prairies with the ERS scatterometer," IEEE Transactions on Geoscience and Remote Sensing, vol. 37, no. 1, pp. 206-216, 1999.

[13] M. Zhribi, C. André, and B. Decharme, "A method for soil moisture estimation in Western Africa based on the ERS scatterometer," IEEE Transactions on Geoscience and Remote Sensing, vol. 46, no. 2, pp. 438-448, 2008.
[14] Klaus Scipal, Wolfgang Wagner, Marco Trommler, and Katrin Naumann, "The global soil moisture archive 1992-2000 from ERS scattterometer dat: First results," in IGARSS'02 Proceedings, Toronto, 2002, IEEE.

[15] Vahid Naeimi, Klaus Scipal, Zoltan Bartalis, Stefan Hasenauer, and Wolfgang Wagner, "An improved soil moisture retrieval algorithm for ERS and METOP scatterometer observations," IEEE Transactions on Geoscience and Remote Sensing, in press.

[16] K. Scipal, M. Drusch, and W. Wagner, "Assimilation of a ERS scatterometer derived soil moisture index in the ECMWF numerical weather prediction system," Advances in Water Resources, vol. 31, pp. 1101-1112, 2008.

[17] A. M. Trofaier, W. G. Rees, A. Bartsch, D. Sabel, and S. Schlaffer, "Thermokarst lake dynamics on the Yamal Peninsula, Siberia," in Geophysical Research Abstracts (EGU General Assembly 2011), 2011, pp. EGU20111314, Vol. 13.

[18] Perry J. Hardin and Mark W. Jackson, "Investigating SeaWinds terrestrial backscatter: Equatorial savannas of South America," Photogrammetric Engineering \& Remote Sensing, vol. 69, no. 11, pp. 1243-1254, 2003.

[19] S. Frolking, M. Fahnestock, T. Milliman, K. McDonald, and J. Kimball, "Interannual variability in North American grassland biomass/productivity detected by SeaWinds scatterometer backscatter," Geophysical Research Letters, vol. 32, pp. L21409, 2005.

[20] W. Wagner, G. Lemoine, M. Borgeaud, and H. Rott, "A study of vegetation cover effects on ERS scatterometer data," IEEE Transactions on Geoscience and Remote Sensing, vol. 37, no. 2, pp. 938-948, 1999.

[21] A. Bartsch, W. Wagner, K. Scipal, C. Pathe, D. Sabel, and P. Wolski, "Global monitoring of wetlands - the value of ENVISAT ASAR global mode," Journal of Environmental Management, vol. 90, pp. 2226-2233, 2009.

[22] CAVM Team, "Circumpolar Arctic Vegetation Map. scale 1:7,500,000," Conservation of Arctic Flora and Fauna (CAFF) Map No. 1. U.S. Fish and Wildlife Service, Anchorage, Alaska, 2003.

[23] B. Heim, J. Boike, M. Langer, S. Muster, J. Sobiech, K. Piel, and A. Bartsch, "The Lena River Delta, Arctic Siberia: An arctic ground data observatory of the DUE Permafrost project," in ESA Living Planet Symposium, Bergen, 2010. 